\title{
Penakrifan Semula Falsafah Sumber Asli untuk Pembinaan Peradaban Islam: Satu Sorotan Awal
}

\author{
Redefining the Philosophy of Natural Resources for the Development of \\ Islamic Civilisation: A Preliminary Review
}

\author{
Fadhilah Othman ${ }^{1}$, Abdul Hafidz Yusoff ${ }^{\mathbb{1}, 2}$, Kamil Azmi Tohiran ${ }^{1,5}$, Fakhruddin \\ Afif Fauzi ${ }^{1,3}$, Norinsafrina Mustaffa Kamal ${ }^{1,4}$ \\ ${ }^{1}$ Komuniti Penyelidik Sumber Asli dan Alam Sekitar (SALAM) \\ ( ${ }^{\circledR}$ Corresponding author: hafidz.y@umk.edu.my) \\ ${ }^{2}$ Faculty of Bioenginering and Technology, Universiti Malaysia Kelantan \\ ${ }^{3}$ Jabatan Mineral dan Geosains Kedah / Perlis / Pulau Pinang \\ ${ }_{4}^{4}$ Pusat Penyelidikan Mineral, Jabatan Mineral dan Geosains Malaysia \\ ${ }^{5}$ Bahagian Penyelidikan Pembangunan Pekebun Kecil, Malaysian Palm Oil Board
}

\begin{abstract}
ABSTRAK
Pembangunan yang digerakkan oleh sesebuah peradaban pastinya memerlukan sumber asli sebagai pemangkin. Justeru falsafah yang mendasari pembinaan sebuah peradaban akan menentukan kesan pembangunan terhadap kelangsungan sumber asli. Walaupun digerakkan dengan ilmu sains tabie yang sama, Islam dan Barat mempunyai pegangan asas yang berbeza dalam pembinaan peradaban masing-masing. Oleh yang demikian cara pengurusan sumber asli serta impak pembangunan yang dikemukakan juga adalah berbeza. Masyarakat Islam pada suatu ketika dahulu telah membina peradaban yang memberi kemakmuran pada kehidupan manusia. Namun, apabila puncak peradaban berpindah tangan kepada masyarakat Barat, kerakusan terhadap sumber asli dan kerosakan terhadap alam sekitar telah menjadi masalah yang tidak dapat dibendung lagi. Bagi memastikan pembangunan dunia pada masa hadapan berada pada landasan yang lestari untuk maslahat generasi seterusnya, artikel ini akan memberi penakrifan semula falsafah sumber asli berdasarkan kajian perbandingan antara pemahaman Islam dengan realiti pemahaman Barat dengan menggunakan kaedah kajian kepustakaan dan analisa perbandingan. Sebagai kesimpulan, manuskrip ini mencadangkan pemakmuran alam sebagai sebuah falsafah baharu sebagai rujukan aspek pengurusan sumber asli sebagai alternatif kepada pembangunan lestari yang dicadangkan oleh Barat.
\end{abstract}

KATA KUNCl

Ketamadunan Islam,

Ketamadunan

Barat,

Pembangunan

Lestari,

Pemakmuran

Alam 


\begin{abstract}
The development driven by a civilisation assuredly requires natural resources as a catalyst. Hence, the philosophy that underlies the construction of a civilisation will determine the impact of the development on the sustainability of natural resources. Although it is driven by the equivalent scientific knowledge, however Islam and West have different fundamental beliefs in the development of their respective civilisations. Therefore, the approach of natural resources management and the impact of development presented are also divergent. In the past centuries, the Muslim community had developed a prosperous civilisation towards human life. However, when the peak of civilisation was taken over by the West, greed for natural resources and damage towards the environment became an unstoppable problem. In order to ensure the development of future world is on a sustainable track for the benefits of the next generation, this manuscript will disclose the differences of philosophical root of natural resources management based on Islamic approach compared to the Western understanding using literature review and comparative analysis. In conclusion, this manuscript proposes the prosperity of nature as a new philosophy as a reference of the management of natural resources aspect as an alternative to the sustainable development as proposed by the West
\end{abstract}

\author{
KEYWORDS \\ Islamic civilisation, \\ western \\ civilisation, \\ sustainable \\ development, \\ nature prosperity
}

\title{
1.0 Pengenalan
}

Perbincangan berhubung pengurusan sumber asli adalah dekat di hati masyarakat kerana ia merupakan isu yang dihadapi saban hari terutama apabila berhadapan dengan masalah kenaikan harga bahan api. Krisis pengurusan sumber asli yang berlaku di negara-negara umat Islam adalah situasi yang mendukacitakan kerana umat Islam selayaknya mendahului dalam pemahaman mereka terhadap hikmah penciptaan alam ini. Terdapat banyak panduan dan hikmah yang diajar dalam Islam berkaitan alam (Jasmi \& Hasan, 2013). Malah, Hamka menyarankan manusia supaya berfikir tentang kejadian alam di sekelilingnya yang terbentang luas sebagai manfaat untuk mengenali dan mendekatkan diri kepada Penciptanya (Yaakob 2012).

Tamadun Islam didasari oleh elemen Tauhid. Teori tauhid Islam mencadangkan satu formula kehidupan yang menyeluruh dan harmoni dengan mewujudkan hubungan yang jelas di antara manusia dengan TuhanNya, hubungan sesama manusia dan juga hubungan manusia dengan alam sekitar yang melangkaui alam metafizik termasuk jin, malaikat, dan alam ghaib yang lain-lain (Mamat \& Mahamood, 2017).

la berbeza dengan tamadun Barat yang menjadikan aspek pemisahan dengan agama (sekular) sebagai sandaran pemacu ketamadunan. Fahaman ini jugalah yang telah melahirkan generasi kapitalis rakus yang menatijahkan penjarahan berlebihan sumber asli bumi dan kerosakan alam sekitar pada hari ini. Oleh itu, manuskrip ini bertujuan untuk mengupas kerangka falsafah sumber alam dari perspektif Islam dan Barat dan menjelaskan perbezaan antara keduanya. Pada akhirnya kajian ini memberikan pentakrifan semula falsafah sumber asli dari perspektif Islam sebagai rujukan pembangunan peradaban baharu Islam.

\subsection{Falsafah Islam dan Barat dalam Pengurusan Sumber Asli}

Manusia secara sedar ataupun tidak telah membangunkan bumi dengan berpandukan kepada falsafah pemahaman mereka terhadap alam. Bagaimana cara manusia memandang dan memahami alam ini akan menentukan cara kehidupan serta corak sesebuah pembangunan. Samada ia bersifat lestari 
ataupun zalim, hasilnya akan memberi impak kepada kesemua komponen alam sekitar termasuk yang berkaitan sumber asli.

Perkembangan falsafah alam sekitar termasuklah pengurusan sumber asli di dalam perbincangan akademik bermula dengan persoalan motivasi moral (etika) manusia terhadap alam. Perkara ini diutarakan melalui pemerhatian terhadap pelbagai kerosakan alam yang berlaku akibat dari aktiviti pembangunan manusia. Sarkar (2014) mengatakan bahawa falsafah alam sekitar adalah perbahasan yang lebih besar daripada etika alam sekitar. Ini kerana di dalam perbahasan ini terdapat isu penting yang dinilai semula iaitu falsafah sains dan epistimologi dalam memahami alam sekitar, peranan manusia serta bagaimana perkaitan manusia dan alam sekitar. Falsafah sains telah beberapa kali berpindah ketuanan antara tamadun Islam dan Barat. Ketuanan falsafah sains ini memberi impak yang besar terhadap alam kerana ia menjadi rujukan utama memahami alam serta membangunkan peradaban di atasnya.

\subsection{Falsafah Pengurusan Sumber Asli dalam Tamadun Islam}

Peradaban Islam yang mengiktiraf peranan akal manusia sebagai kelebihan untuk menjalankan perintah Allah di muka bumi telah memberi kebebasan dan menggalakkan umatnya membangunkan perkembangan ilmu pengetahuan. Ini menyaksikan kelahiran ramai tokoh ilmuan Islam pada zaman Kerajaan Abbasiah sekitar 8 Masihi seperti Jabir ibn Hayyan, Ar-Razi, Ibn Haitam, Ibn Sina dan ramai lagi. Perpustakaan, makmal dan universiti dibina, malah banyak penemuan sains yang lahir ketika itu menjadi asas dalam sains moden dan menggerakkan industri-industri pada hari ini. Kehebatan peradaban Islam dari aspek material pembandaran, keadilan ekonomi, kebudayaan yang unik diakui oleh para pengkaji, bahkan kesan peninggalan kerajaan pemerintahan Islam masih boleh dilihat pada artifak dan tinggalan yang masih terjaga.

Teras utama pemahaman pengurusan alam menurut falsafah Islam adalah dengan i) mengiktiraf Allah SWT sebagai pencipta, pemilik serta pentadbir mutlak alam, ii) akur bahawa manusia adalah makhluk yang diperintahkan dengan ubudiyah dan khalifah, iii) meyakini setiap penciptaan yang lain memiliki keunikan serta iv) meyakini kepelbagaian biologi sebagai manfaat yang mesti dipulihara.

I. Falsafah pengurusan sumber asli pertama menurut Islam adalah pengiktirafan Allah sebagai pencipta, pemilik dan pentadbir alam seperti yang disebut dalam Al-Quran yang bermaksud:

"Dan Dialah yang menciptakan langit dan bumi dengan benar dan benarlah perkataannya pada waktu Dia mengatakan "Jadi lalu jadilah" (Al-An'am 6:73).

Allah SWT mentadbir alam ini dengan meletakkan fungsi serta tugasan khusus kepada segala yang dicipta olehNya. Umumnya, makhluk terdiri daripada dua kumpulan utama iaitu manusia dan jin serta alam semesta (Rajah 1). Kesemuanya adalah makhluk yang diciptakan oleh Allah untuk tujuan yang tertentu, iaitu dengan jin dan manusia melakukan 'ubudiyah kepada Allah. Manakala alam pula dijadikan khusus sebagai tempat tinggal, sumber asas kehidupan manusia dan tempat untuk dimakmurkan sebagai manifestasi 'ubudiyah kepada Allah. 


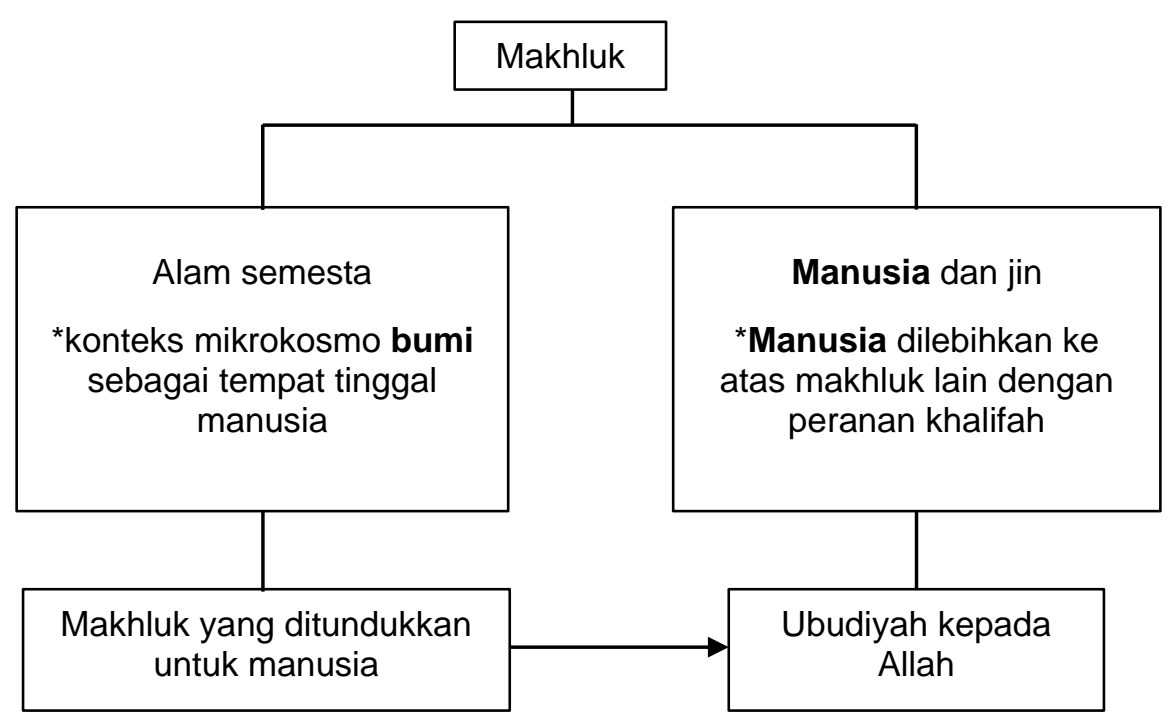

Rajah 1: Perkaitan manusia dan alam sebagai keseluruhan makhluk yang diciptakan Allah SWT.

II. Falsafah pengurusan sumber asli kedua menurut Islam adalah akur bahawa manusia diperintahkan untuk ubudiyah dan khilafah. Allah SWT telah mentakdirkan manusia dengan dua tugas utama iaitu sebagai hamba dan khalifah. Untuk tugas hamba manusia dipertanggungjawabkan untuk melaksanakan 'ubudiyah, iaitu hubungan dengan Tuhan penciptanya. la melibatkan kewajipan peribadi (fardhu ain) sebagai makhluk terutamanya mensucikanNya melalui ibadah-ibadah khusus. Manusia telah diberikan kelebihan ilmu pengetahuan, akal dan keistimewaan lain pada aspek penciptaanNya bagi membolehkan ia memikul tugas sebagai pemimpin kepada makhluk lain (Mamat, 2002). Dengan itu Allah SWT telah melebihkan manusia di atas segala ciptaan (makhluk) yang lain seperti yang diterangkan pada ayat yang bermaksud:

"Dan sesungguhnya Kami telah memuliakan anak-anak Adam; dan Kami telah beri mereka menggunakan berbagai-bagai kenderaan di darat dan di laut; dan Kami telah memberikan rezeki kepada mereka dari benda-benda yang baik-baik serta Kami telah lebihkan mereka dengan selebih-lebihnya atas banyak makhluk-makhluk yang telah Kami ciptakan" (Al-Israa' 17:70).

Kelebihan ini membawa kepada tanggungjawab manusia yang kedua iaitu sebagai khalifah, yang mana ia dituntut untuk melaksanakan tanggungjawab bukan sahaja terhadap sesama manusia, bahkan terhadap makhluk yang lain. Imam Ibn Kathir di dalam tafsirnya telah menerangkan maksud perkataan khalifah-fil-ardh sebagai pelaksana untuk memakmurkannya dari semasa ke semasa bagi digunakan oleh generasi akan datang. Ini bermakna, kesinambungan tugas khalifah bukan terbatas kepada satu generasi atau kumpulan tertentu sahaja, tetapi ia adalah tanggungjawab yang berterusan (Zahari, 2010). Konsep khalifah juga diungkap dengan peranan pengurus sepertimana maksud hadis yang berikut,

"Dunia ini hijau dan cantik dan Tuhan telah melantik kamu sebagai pengurusnya dia melihat apa yang kamu lakukan" - Riwayat Muslim. 
III. Falsafah pengurusan sumber asli ke tiga menurut Islam adalah fungsi unik setiap ciptaanNya. Hakikatnya manusia adalah paksi kerencaman penciptaan makhluk di alam ini. Kerencaman ciptaan Allah SWT ini adalah bagi memudahkan fungsi manusia bertindak sebagai khalifah atau pengurus alam ini. Setiap satu entiti alam telah diciptakan secara unik dan mempunyai peranan masing-masing dalam menyokong kehidupan manusia. Keunikan ini disebut sebagai kadar ataupun ketetapan menurut Al-Quran, serta dapat dihuraikan dengan terperinci menggunakan ilmu sains. Pupus, rosak atau sakitnya satu-satu ciptaan, fungsinya tidak boleh diambil alih oleh ciptaan yang lain.

"Sesungguhnya Kami menciptakan tiap-tiap sesuatu menurut takdir (yang telah ditentukan)" (Al-Qamar 54:49).

Pada prinsipnya, keseluruhan sumber alam diperlukan secara kolektif oleh manusia untuk menjamin kelangsungan kehidupan mereka (Bakar \& Idros, 2007). Manusia telah dapat mengetahui fungsi komponen alam serta cara mendapatkan sumbernya melalui pengetahuan sains dan teknologi moden. Walau bagaimanapun Al-Quran telah terlebih dahulu mengungkapkan contoh-contoh penciptaan alam yang dijelaskan secara terang berhubung fungsi-fungsi setiap komponen ciptaanNya. Jadual 1 menghimpunkan beberapa contoh penjelasan Al-Quran berkenaan komponen utama alam iaitu tanah, air, udara serta biodiversiti. Penjelasan daripada Al-Quran ini ternyata tidak disanggahi ilmu sains yang datang kemudian.

IV. Falsafah pengurusan sumber asli ke empat menurut Islam adalah biodiversiti sebagai manfaat yang mesti dipulihara. Pemuliharaan merujuk kepada perihal (proses, usaha, perbuatan) yang bermaksud untuk memulihara sesuatu (Kamus Dewan Edisi ke Empat). Prinsip pemuliharaan alam sekitar dalam Islam dibina berdasarkan prinsip syarak' 'tidak boleh merosakkan dan tidak boleh mengekalkan kerosakan". Ketika menjalankan fungsinya sebagai khalifah, manusia diwajibkan menjalankan hubungan baiknya dengan alam tabii kerana mereka saling melengkapi antara satu sama lain seperti contohnya manusia menggunakan oksigen dan tumbuhan pula menggunakan karbon dioksida (Bakar \& Idros, 2007). Biodiversiti umumnya merangkumi tumbuhan, haiwan serta mikroorganisma. Menurut (Abu bakar et al,1983), Islam meletakkan biodiversiti sebagai manfaat yang mesti dipulihara kerana manfaat yang sangat penting untuk keperluan hidup manusia. Sebagai contoh, tumbuhan adalah pengeluar utama makanan untuk manusia dan haiwan. Allah SWT memerintahkan manusia untuk memerhatikan makanannya (tumbuhan) tentang bagaimana proses pertumbuhannya berlaku. Firman Allah SWT yang bermaksud:

"Maka hendaklah manusia melihat kepada makanannya (bagaimana kami mentadbirkannya). Sesungguhnya Kami telah mencurahkan hujan dengan curahan yang menakjubkan. Kemudian Kami belah-belahkan bumi dengan belahan yang sesuai dengan tumbuh-tumbuhan. Lalu Kami tumbuhkan pada bumi biji-bijian. Dan buah anggur serta sayur-sayuran. Dan Zaitun serta pohon-pohon kurma, dan taman-taman yang menghijau subur, dan berbagai buah-buahan serta bermacam-macam rumput. Untuk kegunaan kamu dan binatang-binatang ternak kamu" ('Abasa 80:24-32).

Kedua-dua haiwan dan tumbuhan adalah sebahagian daripada komponen utama alam yang mesti diuruskan dengan sebaiknya oleh manusia sebagai sebahagian daripada tindakan pemakmuran bumi. Keterkaitan di antara pelbagai haiwan dan tumbuhan terhadap 
kelangsungan hidup keduanya serta manusia bermakna ia mestilah diurusi dengan cermat. Keterkaitan ini dapat dijelaskan dengan memahami interaksi yang wujud dalam jaringan makanan (food web) setiap organisma. Keperluan asas bagi kelangsungan keragaman ini mestilah dijaga agar pemuliharaan dapat dijalankan. Prinsip keragaman (biodiversiti) yang diwujudkan oleh Allah SWT ini adalah bagi kepentingan dan kelangsungan hidup manusia (Muhammad, 2016). Justeru ia mendasari panduan untuk melaksanakan pemuliharaan alam seperti yang dikehendaki oleh Allah SWT.

Jadual 1: Penjelasan Al-Quran Berkaitan Fungsi Setiap Komponen Alam

\begin{tabular}{|c|c|c|c|}
\hline $\begin{array}{l}\text { Komponen } \\
\text { alam }\end{array}$ & Litosfera & Hidrosfera & Atmosfera \\
\hline $\begin{array}{l}\text { Elemen } \\
\text { penciptaan }\end{array}$ & Tanah & Air & Udara \\
\hline $\begin{array}{l}\text { Fungsi } \\
\text { menurut Al- } \\
\text { Quran }\end{array}$ & $\begin{array}{l}\text { Sebagai tempat tinggal, } \\
\text { penyimpanan dan } \\
\text { penapisan air, pertanian } \\
\text { dan penternakan serta } \\
\text { alat bersuci. }\end{array}$ & $\begin{array}{l}\text { Sebagai sumber makanan, } \\
\text { minuman dan sebagai } \\
\text { medium pengangkutan. }\end{array}$ & $\begin{array}{lr}\text { Sebagai } & \text { agen } \\
\text { pendebungaan dan } \\
\text { pembawa hujan di } \\
\text { tempat-tempat yang } \\
\text { diperlukan. }\end{array}$ \\
\hline Dalil & 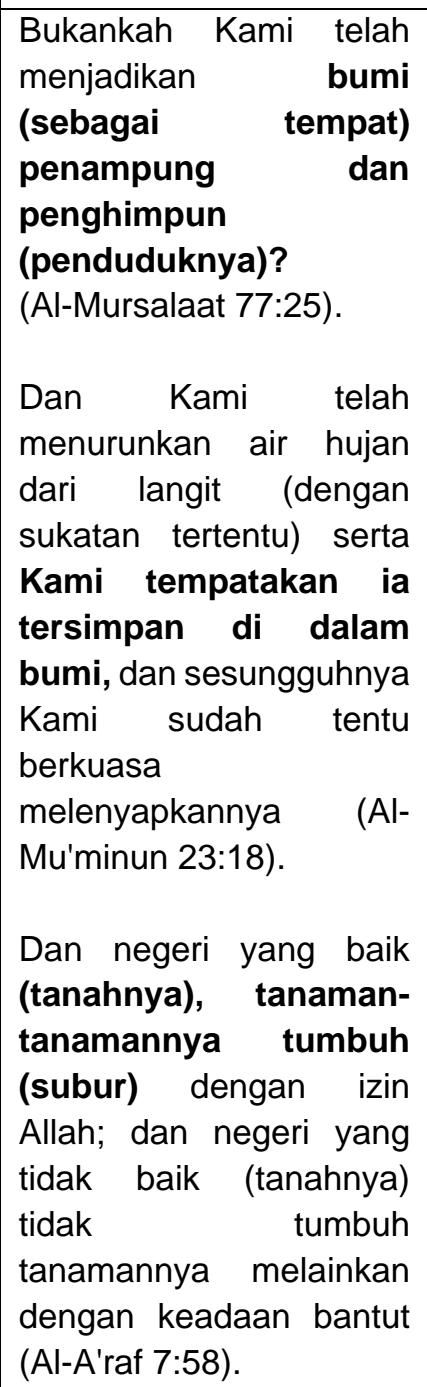 & 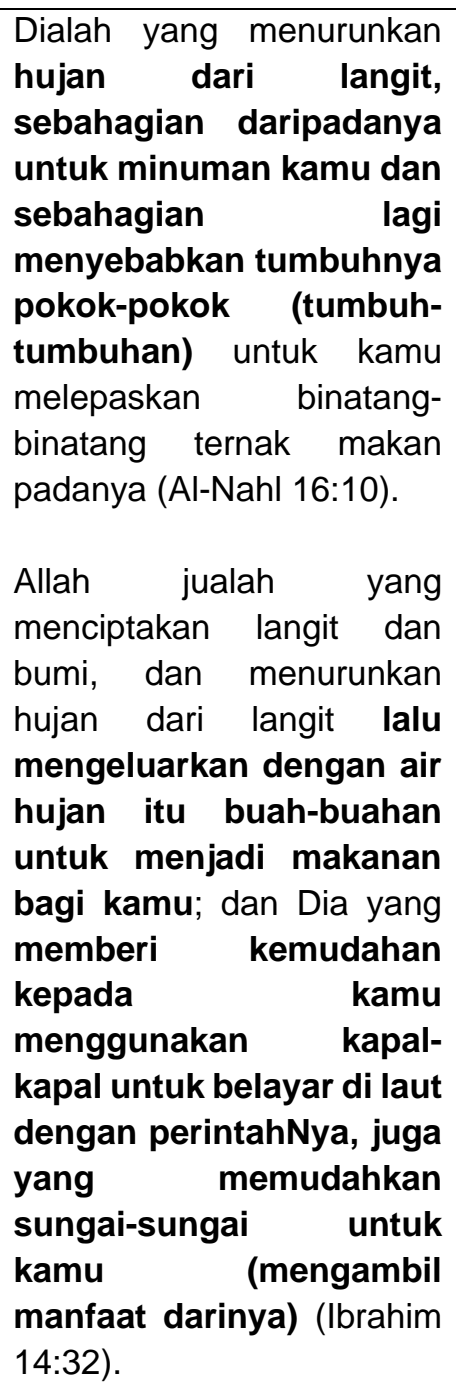 & 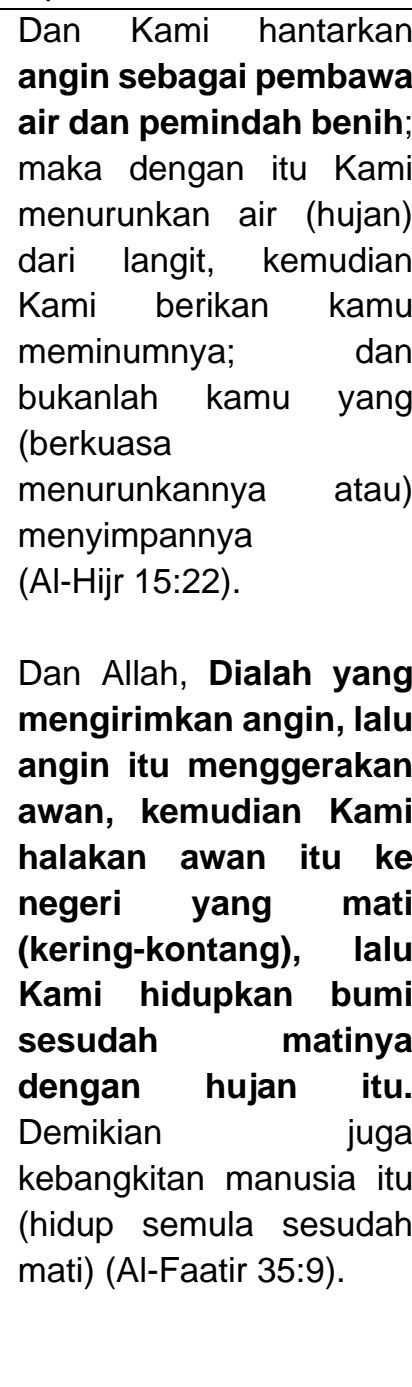 \\
\hline
\end{tabular}


Keempat-empat teras falsafah ini merupakan asas dalam memahami hakikat penciptaan alam dan manusia berdasaran ajaran Islam. Teras ini seterusnya menjadi panduan utama dalam menetapkan nilai etika manusia dalam mengurus tadbir sumber-sumber alam.

\subsection{Falsafah Pengurusan Sumber Asli Menurut Barat}

Keempat-empat teras falsafah ini merupakan asas dalam memahami hakikat penciptaan alam dan manusia berdasaran ajaran Islam. Teras ini seterusnya menjadi panduan utama dalam menetapkan nilai etika manusia dalam mengurus tadbir sumber-sumber alam.

Marsuki (1998) menerangkan pendekatan falsafah Barat dalam pengurusan sumber asli dan alam banyak dipengaruhi oleh perkembangan ilmu sains yang berlaku dalam sejarah tamadunnya. Contohnya menjelang kurun ke-17, masyarakat di Barat giat membincangkan tentang persoalan hakikat alam tabie selaras dengan munculnya sains moden di Eropah. Momentum Zaman Pencerahan (Renaissance) pula telah menjadikan masyarakat Barat mengikat fahaman mereka dengan ideologi humanisme di mana manusia dikatakan sebagai sumber hakikat kebenaran. Akibatnya falsafah masyarakat Eropah dibina berdasarkan penolakan terhadap ajaran agama. Terdapat empat (4) falsafah Barat yang menerangkan bagaimana mereka menguruskan alam iaitu i) empirisme, ii) mekanistik, iii) reduksionitik dan ke iv) darwinisme.

I. Falsafah pengurusan alam pertama mengikut Barat adalah empirisme. Berdasarkan falsafah ini, Barat hanya menerima kaedah saintifik sebagai satu-satunya sumber penghujahan sains moden. Pandangan alam tabie ini hanya dapat diterima melibatkan aspek fizikal sahaja iaitu yang boleh dicerap oleh pancaindera akan kewujudannya. Persoalan alam metafizik telah ditolak kerana ia dikatakan tidak boleh dibuktikan melalui kaedah saintifik.

II. Falsafah kedua adalah mekanistik. Falsafah ini menegaskan bahawa pergerakan objek di alam ini termasuk perilaku manusia adalah berlaku menurut ketetapan alam tabie. Fahaman ini berkembang ekoran penemuan sains dalam pelbagai bidang termasuk astronomi fizik, biologi dan lain-lain. Antara tokoh yang membuat penemuan-penemuan penting termasuk Johanes Kepler (1571-1630 M), Galileo Galilei (1564-1643) dan Isaac Newton (1642-1727). Fahaman ini melihat alam tabie berfungsi seperti gabungan komponen-komponen kecil sebuah mesin. Natijahnya fahaman materialism menjadi subur dalam masyarakat Barat. Alam tabie dinilai hanya terdiri daripada alam benda dan menolak sifat-sifat intrinsik yang wujud pada alam tabii. Keadaan inilah yang mengundang manusia mengeksploitasi alam sekitar dan sumber asli sewenang-wenangnya.

III. Falsafah ketiga adalah reduksionitik. Menurut falsafah ini, seluruh proses yang berlaku di alam tabie termasuk yang melibatkan manusia sebenarnya merujuk kepada fungsi atom. Berdasarkan falsafah ini sesuatu fenomena alam akan dapat difahami jika dapat difahami aspek biologinya, kemudian mengetahui aspek kimianya, fiziknya dan kemudiannya hitungan tabie matematiknya. Kefahaman ini telah diasaskan oleh dua orang tokoh Yunani iaitu Leucippus (475 SM) dan Democritos (460-370 SM). Fahaman ini menolak realiti alam tabie yang saling mempengaruhi antara satu sama lain bagi mewujudkan keseimbangan. Pemisahan ini telah menyebabkan eksploitasi berlebihan manusia terhadap sesuatu sumber tanpa memikirkan kesan langsung daripada tidak balas alam melalui sunnatullah terhadap tindakan mereka.

IV. Falsafah keempat adalah Darwinisme. Falsafah ini adalah berasaskan kepada buku Charles Darwin yang bertajuk "The origin of spesies" pada tahun 1859 (Sussman, 2009). Teori ini cuba menerangkan asal-usul sesuatu spesies termasuk manusia. Darwin percaya bahawa kepelbagaian spesies yang wujud di alam ini adalah disebabkan oleh proses evolusi yang mengakibatkan setiap spesies perlu menyesuaikan diri mereka kepada persekitaran. Proses persaingan tersebut telah membawa kepada kepupusan sesetengah spesies yang dikenali 
sebagai proses natural selection. Kefahaman manusia kepada teori ini telah memberikan kesan terburuk kepada ketamadunan manusia kerana telah memisahkan hubungan sains dengan kebergantungan kepada Pencipta Alam (i.e. Allah SWT).

\subsection{Perbandingan Falsafah Pengurusan Sumber Asli antara Islam dan Barat}

Falsafah Islam terhadap hubungan manusia, alam sekitar serta sumber asli menjurus kepada gagasan pemakmuran bumi yang lestari. Pemakmuran bumi tetap menjalankan aktiviti pembangunan asas seperti pembandaran, pertanian dan perikanan, perlombongan sumber asli serta perdagangan. Kesemua aktiviti ini bahkan boleh dijalankan secara moden dengan mengambil manfaat daripada teknologi semasa. Walau bagaimanapun aktiviti pembangunan ini mestilah dilakukan sebagai wasilah memenuhi perintah ubudiyyah serta tanggungjawab khalifah, dengan erti kata kemaslahatan manusia terjaga serta dalam masa yang sama, komponen dan sumber alam dapat dipulihara.

Berbeza dengan falsafah Barat, di mana pengurusan alam dan sumber asli adalah berdasarkan kepada kaedah saintifik dan teknologi semata mata dengan menolak unsur-unsur agama sebagai sandaran memacu ketamadunan. Peradaban Barat merekodkan pelbagai krisis pengurusan sumber asli dan alam sekitar yang berlaku pada skala yang besar selepas ia mengambil alih ketuanan falsafah sains Islam. Ketika ini peradaban Barat menguasai dunia dengan menjalankan pembangunan yang bersifat humanis. Oleh yang demikian kerosakan-kerosakan alam terus berlaku akibat aktiviti pembangunan yang tidak lestari. Perbandingan falsafah pengurusan sumber asli dan alam sekitar antara Islam dan Barat dapat diringkaskan dalam Jadual 2.

\begin{tabular}{|c|c|c|}
\hline $\begin{array}{l}\text { Elemen } \\
\text { perbandingan }\end{array}$ & Falsafah Islam & Falsafah Barat \\
\hline Epistimologi & $\begin{array}{l}\text { - Wahyu (Al-Quran, Sunnah) } \\
\text { - Sains rabbani }\end{array}$ & $\begin{array}{ll} & \text { Sains atheism } \\
\text { - } & \text { Sains sekular } \\
\text { - } & \text { Pengaruh negatif ajaran Judeo- } \\
& \text { kristianiti terhadap moral manusia }\end{array}$ \\
\hline Ontologi & $\begin{array}{l}\text { - } \text { Manusia adalah makhluk } \\
\text { yang diperintahkan dengan } \\
\text { ubudiyyah oleh Allah SWT } \\
\text { - Khalifah iaitu pemegang } \\
\text { amanah Tuhan - mengurus } \\
\text { alam dengan adil } \\
\text { - Alam ditundukkan kepada } \\
\text { manusia supaya manusia } \\
\text { dapat melaksanakan perintah } \\
\text { ubudiyah dan amanah } \\
\text { khalifah }\end{array}$ & $\begin{array}{l}\text { - Tuhan melantik manusia sebagai } \\
\text { tuan ke atas alam } \\
\text { - Manusia adalah penguasa yang } \\
\text { zalim (bebas buat apa sahaja) } \\
\text { - Alam adalah alat ataupun hamba } \\
\text { untuk mengikut apa sahaja } \\
\text { kehendak tuan atau yang } \\
\text { menguasainya }\end{array}$ \\
\hline Aksiologi etika & $\begin{array}{ll}\text { - } & \text { Pemakmuran alam } \\
\text { - } & \text { Keadilan sosial } \\
& \text { keseimbangan alam }\end{array}$ & $\begin{array}{l}\text { - Utilitarianisme melalui ekonomi } \\
\text { kapitalis } \\
\text { - Pembangunan antroposentrik }\end{array}$ \\
\hline $\begin{array}{l}\text { Sumber } \\
\text { rujukan }\end{array}$ & $\begin{array}{l}\text { - Masyarakat muslim telah } \\
\text { menjadikan syarak sebagai } \\
\text { sistem undang-undang dan }\end{array}$ & $\begin{array}{l}\text { - Tamadun Barat menolak aspek } \\
\text { ketuhanan daripada akidah dan } \\
\text { sains, samada secara total }\end{array}$ \\
\hline
\end{tabular}




\begin{tabular}{|c|c|c|}
\hline & $\begin{array}{l}\text { moral masyarakat, negara } \\
\text { dan menguatkuasakan apa } \\
\text { yang benar dan salah untuk } \\
\text { manusia. Neraca bagi sistem } \\
\text { ini adalah hakikat kebenaran } \\
\text { iaitu Al-Haq yang } \\
\text { bersumberkan Al-Quran dan } \\
\text { Sunnah, di mana natijahnya } \\
\text { ialah kefahaman baharu } \\
\text { tentang alam, termasuk } \\
\text { melalui dapatan ilmu sains, } \\
\text { adalah bebas daripada } \\
\text { kongkongan kehendak nafsu } \\
\text { dan sentiasa selari dengan } \\
\text { kehendak Allah SWT (Negus, } \\
\text { 1997) }\end{array}$ & $\begin{array}{l}\text { (ateisme) ataupun partial } \\
\text { (sekularisme). Ini menyebabkan } \\
\text { tamadun Barat berpegang } \\
\text { kepada humanisme untuk nilai- } \\
\text { nilai sosialnya }\end{array}$ \\
\hline $\begin{array}{l}\text { Elemen } \\
\text { kemanusiaan } \\
\text { dan alam }\end{array}$ & $\begin{array}{l}\text { - Falsafah Islam mengiktiraf } \\
\text { keistimewaan yang terdapat } \\
\text { pada insaniah manusia, iaitu } \\
\text { kemampuan manusia untuk } \\
\text { menjalankan amanah } \\
\text { menguruskan sumber alam } \\
\text { dengan sebaik-baiknya. } \\
\text { Walaubagaimanapun Islam } \\
\text { meletakkan teras-teras yang } \\
\text { mesti memandu insaniah } \\
\text { manusia agar seimbang } \\
\text { tindakannya kepada sesama } \\
\text { makhluk di dunia; serta } \\
\text { seimbang balasan } \\
\text { perbuatannya di akhirat. }\end{array}$ & $\begin{array}{l}\text { - Falsafah humanisme Barat } \\
\text { menafikan keistimewaan pada } \\
\text { insaniah manusia. Etika ekologi } \\
\text { Barat adalah lemah di mana } \\
\text { hubungan dalam jaringan ekologi } \\
\text { hanya melibatkan semata-mata } \\
\text { elemen fizikal kimia dan biologi, } \\
\text { Selain itu, kedudukan manusia } \\
\text { dan spesies lain dalam kosmik } \\
\text { diletakkan sama taraf samada } \\
\text { biota ataupun abiota. }\end{array}$ \\
\hline
\end{tabular}

Masyarakat muslim telah menjadikan syarak sebagai sistem undang-undang dan moral masyarakat, negara dan menguatkuasakan apa yang benar dan salah untuk manusia. Neraca bagi sistem ini adalah hakikat kebenaran iaitu Al-Haq yang bersumberkan Al-Quran dan Sunnah, di mana natijahnya ialah kefahaman baharu tentang alam, termasuk melalui dapatan ilmu sains, adalah bebas daripada kongkongan kehendak nafsu dan sentiasa selari dengan kehendak Allah SWT (Negus, 1997). Di sudut yang lain, tamadun Barat menolak aspek ketuhanan daripada akidah dan sains, samada secara total (atheisme) ataupun partial (sekularisme). Ini menyebabkan tamadun Barat berpegang kepada humanisme untuk nilai-nilai sosialnya

Islam mengiktiraf keistimewaan yang terdapat pada insaniah manusia, iaitu kemampuan manusia untuk menjalankan amanah menguruskan sumber alam dengan sebaik-baiknya. Walau bagaimanapun Islam meletakkan teras-teras yang mesti memandu insaniah manusia agar seimbang tindakannya kepada sesama makhluk di dunia; serta seimbang balasan perbuatannya di akhirat. Falsafah humanisme Barat pula menafikan keistimewaan pada insaniah manusia. Ini menyebabkan etika ekologi Barat lemah di mana hubungan dalam jaringan ekologi hanya melibatkan semata-mata elemen fizikal kimia dan 
biologi, Selain itu, kedudukan manusia dan spesies lain dalam kosmik diletakkan sama taraf samada biota ataupun abiota.

\subsection{Falsafah Pemakmuran Alam dan Sumber Asli sebagai Alternatif Menggantikan Falsafah Barat}

Perbezaan besar yang wujud adalah tamadun Islam telah mengikat sumber panduan pembinaannya kepada Allah SWT pencipta alam ini. la berbeza dengan masyarakat Barat yang hanya bergantung kepada indra dan logik akal semata-mana untuk memahami fenomena alam ini dalam menetapkan batasan tingkah laku mereka. Perbezaan pada sumber utama memahami perkaitan alam dan manusia menyebabkan kedua-dua tamadun mentafsir maklumat, pengalaman hidup dan dapatan kajian secara bertentangan dan menghasilkan solusi yang berbeza. Pembangunan di dunia pada masa depan memerlukan solusi dari Islam kerana hanya pendekatan Islam sahajalah yang bebas daripada prejudis sesuatu kelompok kaum, negara mahupun blok ekonomi. la dilihat dapat memakmurkan kehidupan manusia pada masa ini disamping menjamin kelestarian alam untuk maslahat manusia generasi hadapan.

Secara umumnya pembangunan sumber asli adalah bertujuan untuk mendapatkan aset dan modal kekayaan peradaban untuk diedarkan secara adil kepada masyarakat bagi memenuhi keperluan kehidupan mereka. Islam menegah manusia daripada menggunakannya secara tidak bermoral melalui cara-cara seperti mencuri, menipu, memonopoli, mengeksploitasi, bersifat materialistik dan ego. Ini kerana tindakan negatif yang dilakukan oleh manusia bakal mengundang padah kepada mereka sendiri seperti firman Allah SWT yang bermaksud:

"Dan janganlah kamu makan (atau mengambil) harta (orang-orang lain) di antara kamu dengan jalan yang salah" (Al-Baqarah 2:188).

"(Ketetapan yang demikian) supaya harta itu tidak hanya beredar di antara orang-orang kaya dari kalangan kamu” (Al-Hasyr 59:7).

Dari sudut falsafah sumber alam yang dibahaskan, peradaban baharu Islam perlu dibangunkan dengan tindakan fizikal manusia sebagai khalifah, iaitu dengan memakmurkan bumi. Perintah memakmurkan bumi adalah berdasarkan kepada dalil yang disebutkan di dalam AI-Quran,

"Dan kepada kaum Tsamud (Kami utus) saudara mereka, Soleh. Soleh berkata: Wahai kaumku, sembahlah Allah. Sekali-kali tidak ada Tuhan bagimu selain Dia. Dia telah menciptakan kamu dari bumi (tanah) dan melantik kamu untuk memakmurkannya" (Hud 11:61).

Secara asasnya, pemakmuran ataupun 'imar merujuk kepada usaha-usaha membangunkan bumi dengan mengikut syariat yang diturunkan Allah SWT kepada manusia melalui rasul-rasul Nya. Ini dijelaskan dalam ayat Al-Quran yang berikut,

"Tidakkah mereka telah berjalan dan mengembara di muka bumi, serta memerhatikan bagaimana kesudahan orang-orang yang terdahulu dari mereka? Orang-orang itu lebih kuat daripada mereka sendiri, dan orang-orang itu telah meneroka bumi serta memakmurkannya lebih daripada kemakmuran yang dilakukan oleh mereka, dan orang-orang itu juga telah didatangi oleh Rasul-rasulNya dengan membawa keterangan-keterangan yang jelas nyata (lalu mereka mendustakannya dan kesudahannya mereka dibinasakan). Dengan yang demikian, maka Allah tidak sekali-kali menganiaya mereka, tetapi merekalah yang menganiaya diri sendiri" (Ar-Rum 30: 9). 
Bagi menjalankan peraturan dan hukuman Allah SWT di bumi, khalifah dikehendaki untuk mengerjakan pemakmuran bumi, iaitu menggerakkan aktiviti-aktiviti pembangunan yang dilaksanakan sesuai dengan kehendak dan panduan syara'. Walaupun zaman berubah dan berkembang secara moden sesuai dengan perkembangan ilmu semasa, aktiviti membangunkan bumi masih kekal dijalankan oleh manusia sebagai wasilah bagi mendapatkan manfaat sumber alam yang berada di sekitar untuk kegunaan hidupnya. Ini menjelaskan bahawa tabiat keperluan manusia terhadap alam tidak berubah. Selagi mana manusia bergantung kepada alam untuk kelangsungan hidupnya, ia tetap perlu tunduk kepada syariat Allah dalam menjalankan aktiviti pemakmuran.

\subsection{Kesimpulan}

Daripada perbincangan di atas, dapat dirumuskan bahawa pemakmuran alam dan sumber asli adalah falsafah pembangunan yang lebih tepat untuk diguna pakai dalam pembinaan peradaban yang baharu. Ini bagi menggantikan matlamat kelestarian ataupun pembangunan lestari yang dimulakan oleh tamadun Barat yang mengandungi banyak kelemahan di peringkat falsafahnya. Walaubagaimanapun, pemakmuran bumi hanya dapat dijalankan oleh manusia yang memahami 'ubuddiyah dan menjalankan amanah khalifah yang mana ia dilaksanakan atas dasar kebenaran, tanggungjawab serta keadilan.

\section{Rujukan}

Abou Bakr Ahmed, A.B., Al Sabbagh, A.L.T.El ShirazyAl Glenid, Izzidien, M.A., Samarrai, M.Y. (1983). Islamic Principles for the Conservation of the Natural Environmet. Monograph for IUCN Environmental Policy and Law Paper No 20. Gland, Switzerland, International Union for Conservation of Nature and Natural Resources. https://portals.iucn.org/library/node/6307

Bakar, H. A., \& Idros, S. N. S. (2007). Pemeliharaan alam tabii bersumberkan pengetahuan islam. Pendidikan Sains, 1(7): 31-44.

Jasmi, K. A. \& Hassan, N. (2013). Al-Quran dan Geologi in Geologi, hidrologi, Oceanografi dan Astronomi dari Perspektif al-Quran. Skudai, Johor Bahru: Universiti Teknologi Malaysia Press, pp. 1-19.

Mamat, M. N. (2002). Prinsip dan etika Islam dalam pemuliharaan alam sekitar. Jurnal Tasawwur Islam, 5: 71-81. http://ir.uitm.edu.my/id/eprint/11633

Mamat, M. N., \& Mahamood, S. F. (2017). Islamic philosophy on behaviour-based environmental attitude. Asian Journal of Environment-Behaviour Studies, 2(2): 81-91

Marsuki, M. Z. (1998). Etika Alam Sekitar: Satu Tinjauan Tentang Manifestasinya di Malaysia, unpublished Master dissertation. Kuala Lumpur: Univeristi Malaya.

Muhammad S.G. SRP. (2016). Perlindungan Keanekaragaman Hayati Dalam Hukum Islam. Jurnal Hukum dan Peradilan, 5(1): 73-90.

Negus Y. (1997) Sains dalam Islam. Dalam; Editor Khalid F. M. Islam dan Ekologi. Sahabat Alam Malaysia (SAM), Pulau Pinang. Pp 44-59.

Sussman, H.E. 2009. On the origin of Darwinism. Genome Research 19: 691-692

Sarkar, S. (2014). Environmental philosophy: From theory to practice. Studies in History and Philosophy of Biological and Biomedical Sciences 45 (2014): 89-91.

Yaakob, Z. (2012). Falsafah Alam dalam Konteks Falsafah Ketuhanan Menurut Hamka. International Journal of Islamic Thought, 1: 74-86.

Zahari, M. (2010). Fiqh al-Bi'ah: Prinsip Interaksi Manusia dengan Alam Persekitaran. Jurnal Syariah, Jil. 18, Bil. 1 (2010): 1-24. 